\title{
Inherited prothrombotic states and ischaemic stroke in childhood
}

\author{
V Ganesan, M A McShane, R Liesner, J Cookson, I Hann, F J Kirkham
}

\begin{abstract}
Objective-To investigate the prevalence of currently recognised inherited prothrombotic states in a population of children with arterial stroke.

Methods-Children with arterial stroke presenting to a tertiary level paediatric neurology centre between 1990 and 1996 were investigated for inherited prothrombotic states.

Results-Sixty seven children with arterial stroke were investigated. Abnormalities were initially identified in 16 patients; however, only eight children $(12 \%)$ had an inherited prothrombotic state. This was type 1 protein $S$ deficiency in one patient, the factor $V$ Leiden mutation in six, and activated protein $\mathrm{C}$ resistance (without the factor $\mathrm{V}$ Leiden mutation) in one. The prevalence of the factor $V$ Leiden mutation was not significantly higher in children with arterial stroke $(12 \%)$ than in a control population of children without thrombosis attending the same institution (5.2\%; Fisher's exact test, $p=0.19$; difference in prevalence between patients and controls $(95 \%$ confidence interval $)=6.8 \%$ $(-2.78 \%$ to $16.8 \%))$.

Conclusions-Currently recognised inherited prothrombotic tendencies were rarely associated with stroke in this group of children, although larger numbers of patients would be needed to confirm this. Age appropriate normal values should be used when interpreting the results of a prothrombotic screen. Prothrombotic abnormalities seen acutely are as often transient as inherited. Longitudinal assessment and family studies are required before low concentrations of an anticoagulant protein found acutely can be attributed to an inherited abnormality.

(F Neurol Neurosurg Psychiatry 1998;65:508-511)
\end{abstract}

Keywords: stroke; childhood; prothrombotic states; factor V Leiden

A "prothrombotic screen" will be one of the first investigations requested in many children presenting with acute ischaemic stroke as an association has been reported between inherited prothrombotic states such as inherited protein $\mathrm{C}$, protein $\mathrm{S}$, and antithrombin III deficiencies and premature arterial stroke. In one series of young adult patients these accounted for $25 \%$ of otherwise idiopathic cases. ${ }^{1}$ The literature on the relation between these conditions and arterial stroke in children is mainly anecdotal ${ }^{2}{ }^{3}$ and has recently included an account of an association with the factor $\mathrm{V}$ Leiden (FVL) mutation. ${ }^{4}$

It has been difficult to ascertain from the published data whether inherited prothrombotic states actually cause arterial stroke in childhood as factors which are important in considering this relation are often not given due attention. These include, firstly, the timing of measurements in relation to an acute thrombotic event, secondly, the use of age appropriate normal ranges, and finally the high frequency of asymptomatic heterozygosity for the inherited prothrombotic states in the population as a whole.

To consider this possible association, we undertook a study to investigate the prevalence of inherited protein $\mathrm{C}$ deficiency, protein $\mathrm{S}$ deficiency, antithrombin III deficiency, heparin cofactor II and plasminogen deficiencies, and of activated protein $\mathrm{C}$ resistance (APCr), and the FVL mutation in a population of children with arterial stroke.

\section{Patients and methods}

Patients presenting to Great Ormond Street Hospital for Children NHS Trust with arterial stroke (defined as an acute focal neurological deficit with evidence of cerebral infarction in an arterial distribution on brain CT or MRI) between 1990 and 1996 were investigated. Additional patients were recruited from our paediatric stroke clinic. Patients with cerebral infarction secondary to cerebral venous thrombosis or neonatal stroke were excluded. $\mathrm{Pa}-$ tients were initially investigated as part of their clinical management; however, from 1994 onwards, they were investigated as part of a prospective, ethically approved study.

The following investigations were carried out: full blood count, prothrombin time, activated partial thromboplastin time, thrombin time, fibrinogen and estimation of concentrations of protein $\mathrm{C}$, free and total protein $\mathrm{S}$, antithrombin III, plasminogen, and heparin cofactor II. Patients seen after 1994 also had measurement of the APCr ratio and FVL genotype.

Samples were taken at acute presentation or at the first clinic visit in the patients presenting after the acute event; if any abnormalities were identified, all investigations were repeated after 3 months. In patients in whom venepuncture was difficult, priority was given to estimation of protein $\mathrm{C}$, protein S, antithrombin III concentrations, APCr ratio, and FVL genotype to minimise the volume of blood taken.

In addition to these haematological investigations, patients were investigated for vascular, cardiac, and biochemical risk factors for early stroke. 
Table 1 Results

\begin{tabular}{llll}
\hline Prothrombotic condition & $\begin{array}{l}\text { Children tested } \\
(n)\end{array}$ & $\begin{array}{l}\text { Abnormal results } \\
\text { initially }(n)\end{array}$ & $\begin{array}{l}\text { Persistently } \\
\text { abnormal results } \\
(n(\%))\end{array}$ \\
\hline Factor V Leiden & 50 & 6 & $6(12)$ \\
APC resistance & 50 & 7 & $7(14)$ \\
Protein C deficiency & 67 & 3 & 0 \\
Total protein S deficiency & 65 & 7 & $1^{\star}$ \\
Free protein S deficiency & 59 & 5 & $1^{\star}$ \\
Antithrombin III deficiency & 65 & 1 & 0 \\
Heparin cofactor II deficiency & 58 & 1 & 0 \\
Plasminogen deficiency & 58 & 0 & 0 \\
\hline
\end{tabular}

^In the same patient.

\section{LABORATORY METHODS}

All blood samples were obtained by venepuncture and anticoagulated with $0.109 \mathrm{M}$ trisodium citrate (nine parts blood, one part anticoagulant). They were double centrifuged to remove all residual platelet matter and aliquots of plasma were stored at $-40^{\circ} \mathrm{C}$ until analysis. The prothrombin and activated partial thromboplastin times and fibrinogen were performed by standard automated procedures at $37^{\circ} \mathrm{C}$ and the thrombin time was obtained by manual techniques. Protein C activity was measured by an automatic amidolytic assay using protein $\mathrm{C}$ activator (Unicorn Diagnostics) and a chromogenic substrate (Unicorn Diagnostics). Total and free protein $S$ antigen concentrations were obtained by an enzyme linked immunosorbent assay (ELISA) method performed in microtitre plates using polyethylene glycol precipitation (antibodies supplied by Dako). Antithrombin III, heparin cofactor II, and plasminogen activities were determined by automated amidolytic assays (Immuno for antithrombin III, Rho for heparin cofactor II, Behring for plasminogen). The APCr ratio was measured using the standard APTT based method (Coatest, Chromogenix, Sweden). An $\mathrm{APCr}$ ratio $<2.7$ is considered abnormal in our laboratory. Genomic DNA was extracted from peripheral blood leucocytes by standard procedures for detection of the FVL mutation which was performed using a modification of the original method. ${ }^{5}$

All assays were controlled using normal control plasma (Instrumentation Laboratories) or standard reference plasma (Immuno) and all automated procedures were performed on the ACL 3000 research coagulometer.

CONTROL POPULATION

To estimate the prevalence of the FVL mutation in children without thrombotic problems seen at our institution, 77 randomly selected samples of stored DNA from such children were tested anonymously for the presence of this mutation using the methods described above.

\section{Results}

Sixty seven children with arterial stroke were identified; 49 were recruited at acute presentation and 18 from the stroke clinic. The patients' ages ranged from 2 months to 15 years (median age 6 years); 37 were male. Sixty five children had evidence of cerebral infarction on either CT or MRI of the brain. The remaining two children had bilateral cerebrovascular disease (moyamoya in one and middle cerebral artery (MCA) stenosis in the other) and recurrent transient neurological deficits which were clinically compatible with transient ischaemic attacks.

Table 1 summarises the results. Abnormalities of one or more variables were identified in 16 patients $(24 \%)$ of whom eight patients $(12 \%)$ had an inherited prothrombotic tendency.

Table 2 summarises the details of the eight patients in whom inherited prothrombotic states were identified. None of them or their families gave any history of thrombotic events.

Eight other patients had abnormalities at presentation which resolved within three months of the stroke, except in the one patient who died of intractable intracranial hypertension within 24 hours of presentation.

The prevalence of the FVL mutation in the control population was $5.2 \%$ (4 of 77); this was not significantly different from the prevalence in children with arterial stroke (6 of $50=12 \%$; Fisher's exact test, $\mathrm{p}=0.19$; difference in prevalence between patients and controls (95\% confidence interval $)=6.8 \%(-2.78 \%$ to $16.8 \%))$. A power calculation suggests that a population of at least 250 patients and 250 controls would be needed to confirm that this was the true difference in prevalence.

Taking the prevalence of protein $S$ deficiency to be in the order of $1: 500,{ }^{6}$ the identification of one patient with protein $\mathrm{S}$ deficiency is explicable by chance alone.

\section{Discussion}

The above results suggest that in a group of children with arterial stroke, inherited prothrombotic tendencies were rare and transient deficiencies of the anticoagulant proteins were seen equally often.

Table 2 Details of children with arterial stroke in whom inherited prothrombotic abnormalities were identified

\begin{tabular}{|c|c|c|c|c|}
\hline Patient No & Prothrombotic abnormality & $\begin{array}{l}\text { Cerebrovascular } \\
\text { abnormalities }\end{array}$ & Other risk factors for stroke & Other family members affected \\
\hline 1 & $\begin{array}{l}\text { Type } 1 \text { protein } S \text { deficiency (low } \\
\text { free and total protein } S \text { ) }\end{array}$ & Moyamoya & None & Mother \\
\hline 2 & APC resistance; no FVL mutation & None & Familial hypercholesterolaemia & Father and brother \\
\hline 3 & FVL heterozygote & Moyamoya & $\begin{array}{l}\text { Noonan syndrome, supravalvular } \\
\text { aortic stenosis }\end{array}$ & Not known \\
\hline 4 & FVL heterozygote & MCA stenosis & None & $\begin{array}{l}\text { Not known (father } \\
\text { died after stroke) }\end{array}$ \\
\hline 5 & FVL heterozygote & MCA occlusion & None & Brother \\
\hline 6 & FVL heterozygote & ICA occlusion & None & Not known \\
\hline 7 & FVL heterozygote & None & None & Father \\
\hline 8 & FVL heterozygote & ICA stenosis & None & Not known \\
\hline
\end{tabular}

FVL=factor $\mathrm{V}$ Leiden mutation; $\mathrm{ICA}=$ internal carotid artery; $\mathrm{MCA}=$ middle cerebral artery. 
The FVL mutation is known to increase the risk of venous thrombosis including cerebral venous thrombosis. ${ }^{7}$ Although a possible association between the FVL mutation and stroke in young adults, ${ }^{89}$ children, ${ }^{4}$ and neonates ${ }^{10}$ has been described, a large prospective study failed to show an association with stroke in adults. ${ }^{11}$ The prevalence of this mutation in background populations varies according to the population's composition, a factor which was not considered in any of the previously published accounts of the FVL mutation in juvenile stroke. Ethnicity has been shown to influence the background prevalence $^{12}$ and the age of the population may also be important ${ }^{13}$ and should be considered. Our control population was in the paediatric age group; however, as it comprised children seen at our institution without any thrombotic problems, they did not constitute an entirely "normal" group. It is only reasonable to acknowledge that the numbers in the patient and control groups are small and that a much larger study would be required to confirm our findings. Furthermore, although the FVL mutation on its own may not confer a significant risk of arterial thrombosis, it may do so in conjunction with other abnormalities such as hyperhomocystinaemia. ${ }^{14}$ Such coexistent risk factors for cerebrovascular disease may select out the children with this mutation who develop ischaemic stroke and should be investigated further.

Protein C deficiency, protein S deficiency, and antithrombin III deficiency are the most common of the other inherited prothrombotic states. The medical literature examining the relation between these conditions and premature stroke comprises mainly case reports and rarely considers the question in the light of the background population prevalence or the timing of measurements in relation to the stroke.

Asymptomatic heterozygosity for inherited protein $\mathrm{C}$ deficiency is relatively common, occurring in 1:500 healthy blood donors. ${ }^{6}$ At birth, protein $\mathrm{C}$ concentrations are significantly lower than in adults, and adult values are not reached until the late teenage years. Kennedy et al found the prevalence of low concentrations of protein $\mathrm{C}$ to be as frequent in healthy children as in healthy adults. ${ }^{15}$ Concentrations may also be depressed in association with active thrombosis such as has been reported in association with acute stroke in children ${ }^{16}$ and may not normalise for up to 18 months after the stroke. Even where longitudinal assessment is suggestive of protein C deficiency, it is important that age appropriate norms are used. One of our patients was initially thought to have symptomatic protein $\mathrm{C}$ deficiency after a stroke and was anticoagulated for this for many years but was reclassified as normal after the publication of a paediatric reference range. ${ }^{17}$

The prevalence of primary protein $\mathrm{S}$ deficiency in the population is similar to that of inherited protein $\mathrm{C}$ deficiency; secondary deficiencies are also well recognised. ${ }^{6}$ The most common causes of this are inflammatory illnesses in which the complement system is activated, leading to increased binding of protein $\mathrm{S}$ to $\mathrm{C} 4 \mathrm{~b}$ and a secondary apparent free protein $S$ deficiency. Although there have been anecdotal reports of an association between inherited protein $S$ deficiency and ischaemic stroke, there has not been a case-control study of the prevalence of this abnormality in the juvenile stroke population.

Heterozygous antithrombin III deficiency has a frequency of one in $600 .^{6}$ Although metaanalysis of eight series which investigated adults with stroke under the age of 45 found seven of 311 patients with antithrombin III deficiency, this was only shown to be a persistent abnormality in three patients. ${ }^{1}$

Our data reinforce the importance of longitudinal evaluation with use of age appropriate normal values when identifying inherited prothrombotic states in children. It is, however, important to bear in mind that transient deficiencies of the anticoagulant proteins may be functionally important and may be treatable. For example, one of our patients developed a stroke in the context of purpura fulminans with widespread cutaneous and digital thrombosis after chickenpox, associated with profound protein $\mathrm{C}$, free and total protein $\mathrm{S}$ and antithrombin III deficiencies. She was treated with fresh frozen plasma and protein $\mathrm{C}$ and antithrombin III concentrates to try and minimise the thrombotic damage. All these abnormalities resolved within 1 month.

In the light of our findings, it is also important to recognise that, with the exception of DNA analysis for the factor V Leiden mutation, the diagnosis of the inherited abnormalities we have discussed above can only be made after serial evaluation, once the effects of the acute thrombotic event have resolved. Investigation of the child's parents may be of use in clarifying whether abnormalities identified in the acute phase represent an inherited abnormality. In cases of arterial stroke in which a prothrombotic state is identified, the timing and duration of anticoagulation may need to be considered in individual cases, taking other relevant factors into account. Further work is needed to investigate the importance of newly emerging hereditary prothrombotic states such as mild to moderate hyperhomocysteinaemia and the prothrombin 20210 genotype and their interaction with currently recognised risk factors in the pathogenesis of ischaemic stroke in childhood.

VG and FJK were supported by the Wellcome Trust. We thank Natalie Stern for analysing the control samples and Angie Wade Natalie Stern for analysi
for statistical advice.

1 Barinagarrementaria F, Cantu-Brito C, de la Pena A, et al. Prothrombotic states in young people with idiopathic stroke. A prospective study. Stroke 1994;25:287-90.

2 Israels SJ, Seshia SS. Childhood stroke associated with protein C or S deficiency. $\mathcal{F}$ Pediatr 1989;111:562-4.

3 Vomberg PP, Breervels C, Fleury P, et al. Cerebral thromboembolism due to antithrombin III deficiency in two children. Neuropediatr 1987;18:42-4.

4 Nowak-Gottl U, Strater R, Dubbers A, et al. Ischaemic stroke in infancy and childhood: role of the $\mathrm{Arg}^{506}$ to Gln mutation in the factor V gene. Blood Coagul Fibrinolysis 1996;7:684-8.

5 Beauchamp NJ, Daly ME, Cooper PC, et al. Rapid two-stage PCR for detecting factor V G1691A mutation. Lancet 1994;344:694-5. 
6 DeStefano V, Finazzi G, Mannucci M. Inherited thrombophilia: pathogenesis, clinical syndromes and management ophilia: pathogenesis, clinic
Blood 1996;87:3531-44.

7 Martinelli I, Landl G, Merati G, et al. Factor V gene mutation is a risk for cerebral venous thrombosis. Thromb Haemost 1996;75:393-4.

8 Simoni $\mathrm{P}$, de Ronde H, Prandoni $\mathrm{P}$, et al. Ischaemic stroke in young patients with activated protein $\mathrm{C}$ resistance. A report of three cases belonging to three different kindreds. Stroke 1995;26:885-90.

9 Halbmayer W-M, Haushofer A, Schon R, et al. The prevalence of poor anticoagulant response to activated protein C (APC resistance) among patients suffering from stroke or venous thrombosis and among healthy subjects. Blood Coagul Fibrinolysis 1994;5:51-7.

10 Thorarensen O, Ryan S, Hunter J, et al. Factor V Leiden mutation: an unrecognised cause of hemiplegic cerebral mutation: an unrecognised cause

11 Ridker PM, Hennekens CH, Lindpainter K, et al. Mutation in the gene coding for coagulation factor $\mathrm{V}$ and the risk of myocardial infarction, stroke and venous thrombosis in apparently healthy men. $N$ Engl F Med 1995;332:912-7.

12 Rees DC, Cox M, Clegg JB. World distribution of factor V Leiden. Lancet 1995;346:1133-4.

13 Press RD, Liu X-Y, Beamer N, et al. Ischaemic stroke in the elderly. Role of the common factor V mutation causing resistance to activated protein C. Stroke 1996;27:44-8.

14 Mandel $\mathrm{H}$, Brenner $\mathrm{B}$, Berant $\mathrm{M}$, et al. Coexistence of hereditary homocystinuria and factor V Leiden-effect on thrombosis. N Engl f Med 1996;334:763-8.

15 Kennedy CR, Warner G, Kai M, et al. Protein C deficiency and stroke in early life. Dev Med Child Neurol 1995;37:72330.

16 Dusser A, Boyer-Neumann C, Wolf $M$. Temporary protein C deficiency associated with cerebral arterial thrombosis in childhood. F Pediatr 1988;113:849-51.

17 Andrew M, Vegh $\mathrm{P}$, Johnston $\mathrm{M}$, et al. Maturation of the hemostatic system during childhood. Blood 1992;80:19982005 .

\section{Pneumatic drill through the foramen magnum}
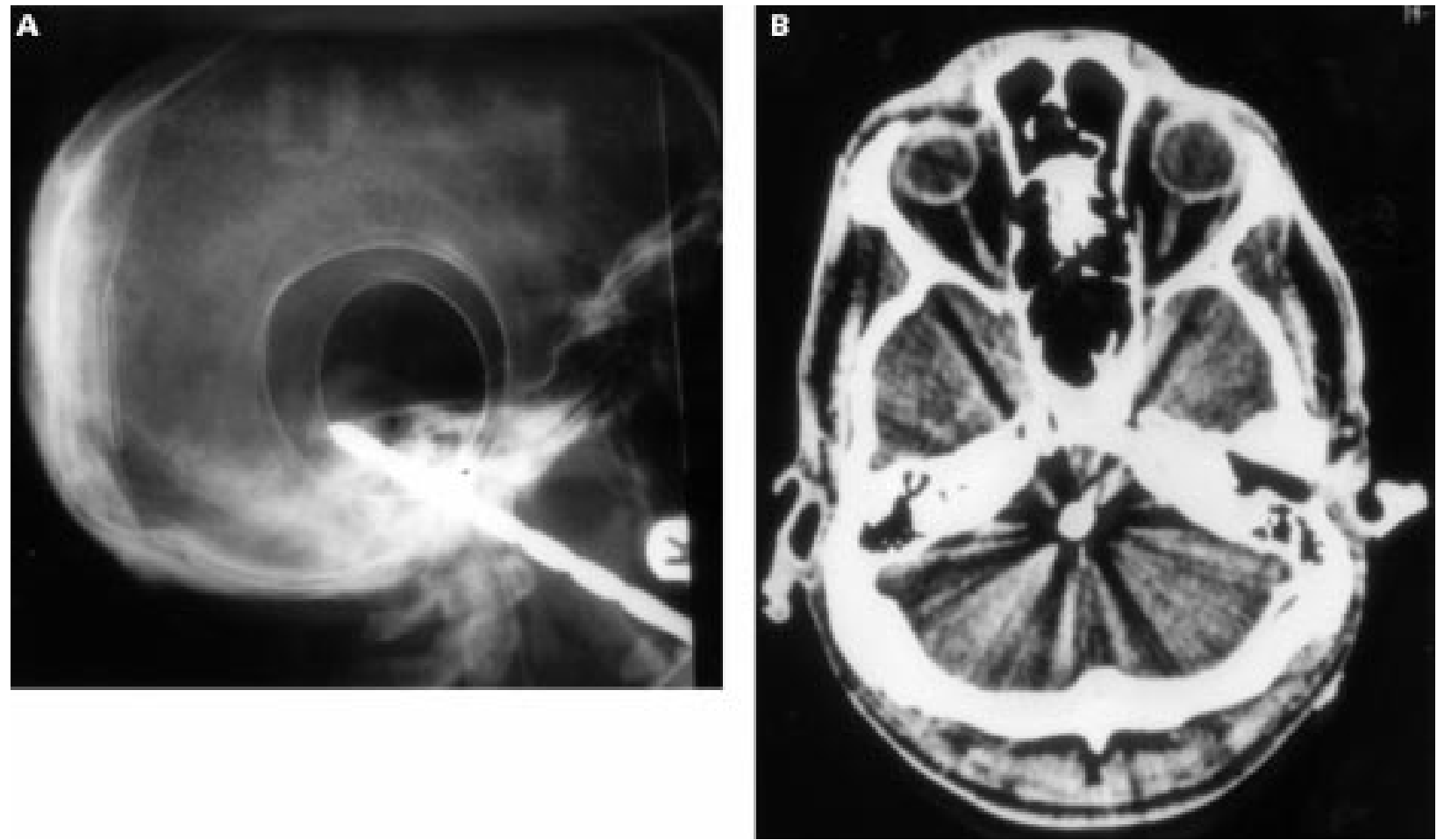

A 29 year old man fell off a ladder while operating a power drill on a building site. The drill became embedded in the patient's face and was still rotating under power when his workmates reached him. The patient was attended by the air ambulance, ventilated, and taken to the casualty department, were the above lateral skull x ray (figure (A)) and CT (figure (B)) were performed. The drill bit entered the face opposite the left lower second premolar tooth, then continued medially, superiorly, and posteriorly to traverse the oropharynx, pass superiorly to the arch of the atlas, through the foramen magnum, crossing the medulla and lower pons, terminating in the right cerebellar hemisphere. The drill bit was removed under sedation. The patient has survived, although he remains tetraplegic. He is able to communicate via a series of blinking movements.

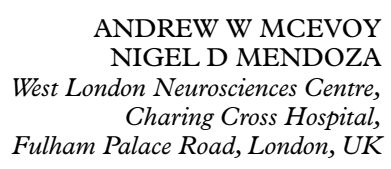

Correspondence to: Dr Andrew W McEvoy, West London Neurosciences Centre, Charing Cross Hospital, Fulham Palace Road, London W6 8RF, UK. 